\title{
Thrombin Levels among Pregnant Women of African Descent in Sokoto, North Western Nigeria
}

\author{
Blessing David Barnabas ${ }^{1}$, Abdulrahman Yakubu ${ }^{1}$, Muktar Yeldu ${ }^{1}$, Isaac Zama ${ }^{1}$, Frank Udomah ${ }^{1}$, Imoru \\ Momodu $^{1}$, Okwesili Augustine ${ }^{1}$, Hauwa Buhari ${ }^{1}$, Festus Uchechukwu Onuigwe ${ }^{1}$, Kwaifa Ibrahim ${ }^{1}$, Aliyu Ibrahim \\ Bagudo $^{1}$, Osaro Erhabor ${ }^{*}$, Daniel Nnadi ${ }^{2}$, Dorcas Ikhuenbor ${ }^{3}$, Festus Aghedo ${ }^{3}$ and Ikechukwu Iwueke ${ }^{4}$ \\ ${ }^{1}$ Department of Hematology and Blood Transfusion, Usmanu Danfodiyo University Teaching Hospital, Nigeria \\ ${ }^{2}$ Department of Obstetrics and Gynecology, Usmanu Danfodiyo University Teaching Hospital, Nigeria
}

${ }^{3}$ Department of Hematology, Usmanu Danfodiyo University Teaching Hospital, Nigeria

${ }^{4}$ Department of Pathology, Federal Neuro Psychiatric Hospital Kware, Nigeria

Submission: May 25, 2017; Published: June 30, 2017

*Corresponding author: Osaro Erhabor, Department of Haematology and Blood Transfusion, Usmanu Danfodiyo University, Nigeria; Tel: 234-813-962-5990;Email: n_osaro@yahoo.com

\begin{abstract}
Aim: The aim of this study was to determine the effect of pregnancy on the thrombin time when compared with of non-pregnant control women.

Background: Pregnancy is the fertilization and development of one or more offspring, known as an embryo or foetus in a woman's uterus Pregnancy is characterized by an increase in plasma concentration of several coagulants.

Design: This is a case- control study designed to include 100 pregnant women as the subjects and 50 non-pregnant women as controls

Methods: The thrombin time was determined using Thrombin reagent produced by Diagnostic Reagents Ltd (UK). Thrombin time of pregnant subjects were compared with that of non-pregnant controls.

Result: The thrombin time of 100 consecutively-recruited pregnant women and 50 non-pregnant women (as controls) were studied. The mean age and range of pregnant subjects were aged $25.52 \pm 4.92$ years and 18 to 34 . The thrombin time of pregnant women was shorter (14.35 \pm 1.69 seconds) compared to that of non-pregnant women $(21.84 \pm 0.77$ seconds) ( $\mathrm{p}=0.001)$. The mean $\mathrm{TT}$ of the pregnant subjects was compared based on trimester, and the mean thrombin time was significantly higher $(p=0.05)$ among pregnant women in the first trimester $(15.1 \pm 2.0$ seconds) compared to the second $(14.2 \pm 1.6$ seconds) and third trimester $(14.1 \pm 1.5$ seconds $)(p=0.05)$.
\end{abstract}

Conclusion: This study has shown that variations in the thrombin levels are evident in pregnancy. The results of this research work conclude that there is a significant difference in thrombin levels in pregnancy when compared with non-pregnant control women.

\section{Introduction}

Coagulation is the process by which blood forms clot. It is an important part of haemostasis; the cessation of blood loss from a damage vessel, where by a damaged blood vessels wall is covered by a platelet and fibrin containing clot to stop bleeding and begin repair of haemorrhage or obstructive clotting [1]. Coagulation begins almost instantly after an injury to the blood vessels has damaged the endothelial lining the vessel.

Thrombin is an enzyme that presides over the conversion of fibrinogen to fibrin. Thrombin is the essential enzyme product of the blood coagulation enzymatic cascade. It is a "trypsin-like" serine protease protein that in humans is encoded by the F2 gene [2]. Prothrombin (coagulation factor II) is proteolytically cleaved to form thrombin in the first step of the coagulation cascade, which ultimately results in the stemming of blood loss. Thrombin in turn acts as a serine protease that converts soluble fibrinogen into insoluble strands of fibrin, as well as catalyzing many other coagulation-related reactions. In the blood coagulation pathway, thrombin acts to convert factor XI to XIa, VIII to VIIIa, V to Va, and fibrinogen to fibrin. In a country like Nigeria, high maternal mortality and foetal wastage is associated with high incidence of ante partum and post-partum haemorrhage, high parity, high case of unbooked pregnant women turn up in labour without any antenatal care, high patronage of unqualified traditional birth attendants (TBA's), home deliveries not supervised by trained personnel, inadequate and inaccessible health facilities and late 
presentation of cases to health facilities [2,3]. There is paucity on the thrombin time among pregnant women of African descent in Sokoto, Nigeria.

Pregnancy is a risk factor for venous thrombosis. Venous thromboembolism is an important cause of maternal morbidity and mortality. There is need to evaluate the effect of pregnancy on haemostatic parameters (TT) in other to reduce the risk of development of thromboembolism and excessive loss of blood during delivery and improve the antenatal care given to pregnant women. The aim of this study is to determine the effect of pregnancy on the thrombin time of women attending antenatal clinic in Specialist Hospital Sokoto State of Nigeria. The Specific Objectives were; to determine the effect of pregnancy on the thrombin concentration of pregnant women in Sokoto, Nigeria, to compare the thrombin time of pregnant and non- pregnant women in Sokoto, Nigeria and to determine the effect of trimester on the thrombin time of pregnancy women in Sokoto, Nigeria. Information on this study will be used to improve the management of haemostatic complications associated with pregnancy and will help improve the quality of antenatal care offered to pregnant women in the State.

\section{Materials and Methods}

\section{Study area}

This study was conducted in the Specialist Hospital Sokoto State. Sokoto is a city located in the extreme Northwest of Nigeria, near to the confluence of the Sokoto River and the Rima River. The metropolitan city of Sokoto covers an area of $60.33 \mathrm{~km}$ (Collins Maps, 2013). It is in the dry Sahel surrounded by sandy savannah with an annual average temperature of $28.3^{\circ} \mathrm{C}\left(82.9^{\circ} \mathrm{F}\right)$. The warmest months are February to April, the rainy season is from June to October, during which showers are a daily occurrence. From late October to February, during the 'cold season', the climate is dominated by the Harmattan wind blowing Sahara dust over the land. Sokoto State has a projected population of 3.7 million people based on 2006 census. The State is made up of two major ethnic groups namely, Hausa \& Fulani [4]. All the samples collected ( $4.5 \mathrm{mls}$ citrated venous blood) were analyzed at the Haematology Department of Usmanu Danfodiyo University Teaching Hospital (UDUTH) Sokoto. It is among the Hospitals that were established in May 1980 as a second-generation teaching hospitals along with Calabar, Port Harcourt, Ilorin, Maiduguri and Jos. The hospital started operating at the Specialist hospital, Sokoto. It has witnessed different kinds of transformations in recent years which have translated into the provisions of tertiary health care service to the entire Northwest region.

\section{Sample population}

The study population comprised of adult pregnant visiting the antenatal clinic in Specialist Hospital Sokoto. The control participants were age-matched, non-pregnant women residing in Sokoto metropolis. Subjects and control participants were aged 18-40 years.

\section{Study design}

This is a case control study designed to include 100 pregnant women as the subjects and 50 non-pregnant women as controls.

\section{Eligibility criteria}

All consenting adults ( $\geq 18$ years) pregnant (subjects) and non-pregnant (controls) without any history of bleeding disorders or oral anticoagulants use were excluded from the study. Control participant were non-menopausal and non- menstruating.

\section{Exclusion criteria}

All women who do not meet the eligibility criteria are excluded from this study. Menopausal and menstruating women are also excluded as control. Pregnant and control subjects with bleeding disorders, underlying coagulation disorders, pregnancy related problem, patients on anticoagulants therapy and patients that refused to give consent were excluded.

\section{Sample collection}

For each subject a tourniquet was applied around the arm, the antecubital fosa was disinfected with cotton wool soaked in methylated spirit. About $4.5 \mathrm{mls}$ of venous blood was collected using a $5 \mathrm{mls}$ syringe into sodium citrate anticaogulated tube. The blood was centrifuged to obtain citrated plasma. The citrated plasma was used for the determination of fibrinogen and thrombin concentration.

\section{Methods}

Thrombin Time Test

\section{Principle}

Thrombin time is proportional to fibrinogen concentration of the plasma. The thrombin time was determined using Thrombin reagent produced by Diagnostic Reagents Ltd (UK).

\section{Procedure}

A. Two hundred micro liters $(200 \mu \mathrm{l})$ of patient plasma was added to a test tube and warmed at thirty-seven degree (370 $\stackrel{\circ}{ }$ ).

B. One hundred micro liters $(100 \mu \mathrm{l})$ of bovine thrombin was added.

C. The thrombin time was recorded using a stopwatch as the time taken to form a clot following the addition of the bovine thrombin.

\section{Reference Range for Thrombin}

The normal range for Thrombin is 15-23 seconds.

\section{Statistical Analysis}

Data obtained was entered manually into computer statistical software (SPSS version 20.0). Results were expressed as mean \pm standard deviation. Student t-test was used to compare means difference of FIBC and Thrombin between pregnant and 
non- pregnant women. A p-value of $\leq 0.05$ was considered as statistically significant in all statistical comparisms.

\section{Results}

The thrombin time of 100 consecutively-recruited pregnant women and 50 non-pregnant women (as controls) were studied. The mean age and range of pregnant subjects were aged $25.52 \pm 4.92$ years and 18 to 34 . The mean thrombin time observed among the pregnant subjects was 14.35 Seconds. Table 1 shows the mean Thrombin Time of pregnant subjects and the nonpregnant controls. The mean of TT observed among the pregnant subjects was compared against the non -pregnant controls. The TT $(\mathrm{p}=0.001)$ was shorter among the pregnant subjects $(14.35 \pm 1.69$ Seconds) respectively compared to the non-pregnant controls (21.84 \pm 0.771 .69 Seconds).

Table 1: Table of values showing Mean Thrombin Time of Pregnant Subjects and Non- Pregnant Controls.

\begin{tabular}{|c|c|c|c|c|c|}
\hline Haemostatic Parameter & Pregnant Subjects & Non-Pregnant Controls & $\mathbf{T}$ & df & P-Value \\
\hline Thrombin (Seconds) & $14.35 \pm 1.69$ & $21.84 \pm 0.77^{* * *}$ & -37.32 & 146.93 & 0.001 \\
\hline
\end{tabular}

*** statistically significant $(p<0.001)$ as compared to control. The thrombin time of pregnant women was shorter $(14.35 \pm 1.69$ seconds) compared to that of non-pregnant women $(21.84 \pm 0.77$ seconds).

Table 2: Table of values showing Mean Thrombin Time among Pregnant Subjects based on trimesters.

\begin{tabular}{|c|c|c|}
\hline \multirow{2}{*}{ Trimester } & Number & \multirow{2}{*}{ Thrombin (Seconds) } \\
\cline { 2 - 3 } & $\mathbf{X} \pm \mathbf{S D}$ & $15.05 \pm 1.5^{\mathrm{b}}$ \\
\hline $1^{\text {st }}$ Trimester & 22 & $14.23 \pm 1.6^{\mathrm{ab}}$ \\
\hline $2^{\text {nd }}$ Trimester & 31 & $14.11 \pm 2.0^{\mathrm{a}}$ \\
\hline $3^{\text {rd }}$ Trimester & 47 & 0.05 \\
\hline Significance & & 0.05 \\
\hline
\end{tabular}

The mean thrombin time was significantly higher $(p=0.05)$ among pregnant women in the first trimester $(15.1 \pm 2.0$ seconds) compared to the second (14.2 \pm 1.6 seconds) and third trimester (14.1 \pm 1.5 seconds). The results conclude that there is a significantly shorter thrombin time in the first trimester compared to the second and 3rd trimesters.

Table 2 shows the mean thrombin time among the pregnant subjects based on trimesters. The mean TT of the pregnant subjects was compared based on trimester. The mean thrombin time was significantly higher $(\mathrm{p}=0.05)$ among pregnant women in the first trimester $(15.1 \pm 2.0$ seconds $)$ compared to the second $(14.2 \pm 1.6$ seconds $)$ and third trimester $(14.1 \pm 1.5$ seconds $)$.

The mean thrombin time was significantly higher $(p=0.05)$ among pregnant women in the first trimester $(15.1 \pm 2.0$ seconds) compared to the second $(14.2 \pm 1.6$ seconds) and third trimester (14.1 \pm 1.5 seconds). The results conclude that there is a significantly shorter thrombin time in the first trimester compared to the second and 3rd trimesters.

\section{Discussion}

Physiological changes in pregnancy affect the coagulation and fibrinolytic systems. Many of the clotting factors increase and anticoagulation factors decrease causing augmented coagulation and decreased fibrinolysis. Pre-existing coagulopathies may affect the course of pregnancy and nature of coagulopathy may also be modified by pregnancy. Changes in coagulation affect the mode of delivery. Haemostatic abnormalities have been associated with various complications of pregnancy [5]. This research work was carried out to assess the Thrombin time of pregnant women in Sokoto North Western Nigeria compared to the non-pregnant controls.
This study indicated a statistically significant lower Thrombin time among pregnant subjects compared to the non-pregnant controls $(\mathrm{p}=0.001)$. This finding is consistent with previous report [6] which indicated that TT is slightly decreased in pregnancy and that this increase was a result of increased thrombin generation in pregnancy which also accounts for the hypercoagulability state in pregnancy, and also as a result a gross elevation of fibrinogen concentration [7]. Thrombin time is a function of the fibrinogen concentration in Plasma. Previous reports [8-12] indicated a significant increase in fibrinogen concentration during pregnancy. Pregnancy is known to be a procoagulable state; therefore, it is not surprising that this study and other studies have observed an increase in fibrinogen the precursor of fibrin beginning in early pregnancy [13-15].

Thrombin is the essential enzyme product of the blood coagulation enzymatic cascade. Thrombin is a "trypsin-like" serine protease protein that in humans is encoded by the F2 gene [2]. Prothrombin (coagulation factor II) is proteolytically cleaved to form thrombin in the first step of the coagulation cascade, which ultimately results in the stemming of blood loss. Thrombin in turn acts as a serine protease that converts soluble fibrinogen into insoluble strands of fibrin, as well as catalyzing many other coagulation-related reactions. In the blood coagulation pathway, thrombin acts to convert factor XI to XIa, VIII to VIIIa, V to Va, and fibrinogen to fibrin.

It was also observed during the course of this research that trimester affects coagulation. We observed that Thrombin time was higher among pregnant women in the first trimester of pregnancy compared to the second and third trimester. This finding is at variance with a previous report by [8] which showed that thrombin level increased significantly in the third trimester when compared to first and second trimester. In pregnancy, physiological changes affect coagulation and fibrinolytic system. These physiological changes are seen in blood volumes, blood pressure, gastrointestinal system, metabolism, renal physiology, the endocrine system, haematological parameters, liver enzymes [16]. Many clotting factors increase and anticoagulation factors decrease causing augmented coagulation and decrease 
fibrinolysis [17]. Haemostasis abnormalities have been associated with various complications of pregnancy [5]. These changes in haemostatic system are considered to be in preparation for the maintenance of the placental function which occurs during pregnancy. These substances stimulate clot formation to stop maternal blood loss. As placental blood flow is up to $700 \mathrm{ml} / \mathrm{min}$ considerable haemorrhage can occur if clotting fails. Pregnancy is a complex physiological process with many physiological changes as seen in increased coagulation factors and decreased anticoagulation factors. During pregnancy, there are significant changes in coagulation in the direction of coagulability, thus decreasing bleeding complications in connection with delivery [18].

Finding from this study is in agreement with previous report that during normal pregnancy the haemostatic balance changes in the direction of hypercoagulability with increase in fibrinogen level and a decrease in thrombin time, thus decreasing bleeding complications in connection with delivery [19-23]. Previous report by Hui et al. [24] on their cohort of 58 women with singleton pregnancies observed that the levels of fibrinogen and thrombin time were higher in early pregnancy than those in nonpregnant controls.

In this present study, the thrombin time was lower in pregnant women than in non-pregnant women. This finding indicates that the haemostatic reference intervals being used generally based on samples from non-pregnant women may not be correct, is not relevant to pregnant women and can potentially hinder the accurate diagnosis and treatment of haemostatic disorders during pregnancy. This observation is consistent with previous reports which suggest that gestational age-specific reference values are essential for the accurate interpretation of a subset of haemostatic tests during pregnancy, delivery, and puerperium [25,26]. Similarly, Réger et al. [27] reported in a previous study that normal pregnancy is associated with hypercoagulable state. Elevated markers of coagulation and fibrinolytic system activation indicate increased thrombin activity and increased fibrinolysis following fibrin formation throughout pregnancy. These changes exceed the biological variability in most cases. Haemostatic reference intervals are generally based on samples from non-pregnant women. Thus, they may not be relevant to pregnant women, a problem that may hinder accurate diagnosis and treatment of haemostatic disorders during pregnancy.

\section{Conclusion}

This study has shown that variations in the thrombin levels are evident in pregnancy. The results of this research work conclude that there is a significant difference in Thrombin levels in pregnancy when compared with non-pregnant control women.

\section{Recommendations}

Finding from this study is a wakeup call on the need to routinely monitor haemostatic parameters of pregnant women.
There is need to develop haemostatic reference intervals for pregnant women in the area. Current reference intervals being used are generally based on samples from non-pregnant women. This may hinder the accurate diagnosis and treatment of haemostatic disorders during pregnancy. It is recommended that pregnant women with haemostatic complications should be under the management and care of a qualified obstetrician to mitigate the possible negative effect during pregnancy and delivery. There is also the need to provide the necessary facilities and trained Medical Laboratory Scientist to facilitate the effective diagnosis and monitoring of haemostatic disorders associated with pregnancy.

\section{Referances}

1. David L, Nigel K, Michael M, Denise OS (2009) Practical Hemostasis and Thrombosis. Wiley-Blackwell. pp. 1-5.

2. Degen SJ, Davie EW (1987) Nucleotide sequence of the gene for human prothrombin. Biochemistry 26(19): 6165-6177.

3. Akani CI, Erhabor O, Allagoa DO (2010) Human immunodeficiency virus prevalence in an unbooked obstetric population in the Niger Delta. HIV AIDS (Auckl) 2: 179-184.

4. (2013) United Nations Fund for Population Activities (UNFPA): Population Projection and Health Care Services in Sokoto State, Nigeria.

5. Awodu OA, Enosolease ME (2003) Activated thromboplastine time in women with recurrent spontaneous abortions. Ann Biomed Sci 2(1): $42-46$.

6. Uchikova EH, Ledjev IL (2005) Changes in haemostasis during pregnancy. Euro J Obstet Gynaecol Reprod Biol 119(2): 185-188.

7. Dacie JV, Lewis SM (2002) Practical Haematology, Ninth Edition. Churchill Livingstone: 344-353.

8. Amilo GI, Anokwute MU, Ifeanyichukwu MO, Chukwuanukwu O, Ifediata F, et al. (2013) Fibrinogen Concentration and thrombin levels in pregnant women in Nnewi, Anambra State, South, Eastern Nigeria. J Biol, Agric Health 3(7): 14.

9. Duperray A, Languino LR, Plescia J, McDowall A, Hogg N, Craig, et al. (1997) Molecular identification of a novel fibrinogen binding site on the first domain of ICAM-1 regulating leukocyte-endothelium bridging. Biol Chem 272: 435-441.

10. Hellgren M (2003) Hemostasis during normal pregnancy and puerperium. Semin Thromb Hemost 29(2):125-130.

11. Imoru M, Emeribe AO (2008) Haemorrheologic profiles in apparently healthy pregnant women in Calabar, Nigeria. Afri J Biotech 7(24): 4354-4358.

12. Romero R, Rosner BA, Willett WC (2007) Inflammation in pregnancy: its roles in reproductive physiology, obstetrical complications, and foetal injury. Nutr Rev 2: 194-202.

13. O'Riordan MN, Higgins JR (2003) Haemostasis in normal and abnormal pregnancy. Best Pract Res in Clin Obstet and Gynaecol 17(3): 385-396.

14. Bonnar J, McNicol GP, Douglas AS (1969) Fibrinolytic enzyme system and pregnancy. Br Med J 3(5667): 387-389.

15. Stirling Y, Woolf L, North WR, Seghatchian MJ, Meade TW (1984) Haemostasis in normal pregnancy. Thromb Haemost 52(2): 176-182.

16. Jamjute P, Ahmad A, Ghosh T (2009) Liver function test and pregnancy. J Matern Fetal Neonatal Med 22(3): 274-283. 
17. Thorton P, Dauglas J (2010) Physiological changes to coagulation during pregnancy. Best Practice and Research Clinical Obstetrics and Gynaecology 24: 339-352.

18. Olorunshola KV, Achie LN, Malik HL, Avidime S (2011) Prothrombin Time, Clotting Time, Platelet Concentration and Haematocrit During Labour and Postpartum of Women in Zaria, Northern Nigeria. Asian Journal of Medical Sciences 3(4): 170-175.

19. Asakura $H$ (2011) Interpretation of hemostatic and fibrinolytic markers. Rinsho Byori 59(10): 970-977.

20. Borrelli AL, De Lucia D, Bernacchi M, Napolitano M, Di Domenico A, et al. (2006) Haemocoagulative modifications correlated with pregnancy. Minerva Ginecol 58(4): 315-322.

21. Brenner B (2004) Haemostatic changes in pregnancy. Thrombosis and Haemostasis 114(5-6): 409-414.

22. Chen LB, Meng LL, Chen H, Du BJ, Zhu LQ et al. (2013) Coagulation and prothrombotic state parameters: clinical analysis in early pregnancy. Zhonghua Yi Xue Za Zhi 93(27): 2146-2148.

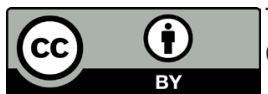

This work is licensed under Creative Commons Attribution 4.0 License
23. Szecsi PB, Jørgensen M, Klajnbard A, Andersen MR, Colov NP, et al. (2010) Haemostatic reference intervals in pregnancy. Thromb Haemost 103(4): 718-727.

24. Hui C, Lili M, Libin C, Rui Z, Fang G, et al. (2012). Changes in coagulation and hemodynamics during pregnancy: a prospective longitudinal study of 58 cases. Arch Gynecol Obstet 285(5): 1231-1236.

25. Hansen AT, Andreasen BH, Salvig JD, Hvas AM (2011) Changes in fibrin D-dimer, fibrinogen, and protein S during pregnancy. Scand J Clin Lab Invest 71(2): 173-176.

26. Wang M, Lu S, Li S, Shen F (2013) Reference intervals of D-dimer during the pregnancy and puerperium period on the STA-R evolution coagulation analyzer. Clin Chim Acta 425: 176-180.

27. Réger B, Péterfalvi A, Litter I, Pótó L, Mózes R, et al. (2013) Challenges in the evaluation of D-dimer and fibrinogen levels in pregnant women. Thromb Res 131(4): e183-e187.

Your next submission with Juniper Publishers will reach you the below assets

- Quality Editorial service

- Swift Peer Review

- Reprints availability

- E-prints Service

- Manuscript Podcast for convenient understanding

- Global attainment for your research

- Manuscript accessibility in different formats

( Pdf, E-pub, Full Text, Audio)

- Unceasing customer service

Track the below URL for one-step submission https://juniperpublishers.com/online-submission.php 